\title{
DIURNAL VARIATIONS OF AEROSOL TRACE ELEMENT CONCENTRATIONS AS DETERMINED BY NONDESTRUCTIVE NEUTRON ACTIVATION ANALYSIS
}

\author{
K. A. RAHN, R. Dalrs, ${ }^{*}$ J. A. RobBns and J. W. Winchester $†$ \\ Dept. of Meteorology and Oceanography and Great Lakes Research Division, University of \\ Michigan, Ann Arbor, Michigan 48104, U.S.A.
}

(First received 27 .April 1970 and in final form 13 August 1970)

\begin{abstract}
Diurnal concentration variations of 20 trace elements in surface air have been studied over a 34-h period in a rural area. Twenty-five millimetre polystyrene air filter samples were taken each $90 \mathrm{~min}$ and analyzed by nondestructive neutron activation analysis using $\mathrm{Ge}(\mathrm{Li})$ gamma-spectrometry and computer assisted data handling. Basic diurnal patterns are related to meterological variables but variations from element to element are ascribed to differences in particle size distributions as determined by an Andersen Cascade Impactor. The behavior and particle size distribution of some elements suggested local sources.
\end{abstract}

\section{INTRODUCTION}

A STUDY of the diurnal concentration variations of atmospheric trace elements has recently been begun, as part of a larger study of their general atmospheric behavior. Previous investigations of daily patterns of pollution concentrations have been both theoretical (Hewson, 1960; U.S. Department of Health, Education and Welfare, 1965) and empirical (Commins, 1967; Munn, 1959; Summers, 1966; Weisman, 1969; U.S. Public Health Service, 1968) where in the latter cases soiling index, smoke, sulfur dioxide, nitrogen oxides and total particulate have served as indicators. To our knowledge, however, daily variations of individual trace elements have not yet been reported. Previous studies have all been in urban areas, whereas a rural setting was chosen for this investigation in an attempt to minimize the effects of source processes and urban micrometeorology relative to the mesometeorology.

This study was made possible by the recent development by the authors of a technique for nondestructive neutron activation analysis of aerosols collected on a high purity filter (DAMs, 1970) in which up to 33 elements may be determined from 24 hour samples, many of which are recognized as being of pollution origin. Diurnal studies require sample lengths as short as possible, and the extreme sensitivity of neutron activation allows the determination of at least 15 elements in samples collected for as short a time as $90 \mathrm{~min}$. In an effort to better correlate time variation patterns from element to element, particle size distributions were measured concurrently.

\section{SAMPLING}

Sequential 90 min filter samples were taken throughout the period, using a polystyrene material (DAMs, 1971) which combines good filtering performance with reasonably high purity. A high flow rate per unit surface area was achieved through the combination of a high vacuum pump (Gelman twin cylinder) and $25 \mathrm{~mm}$ dia. filter holders. Such a system produces flow rates through the polystyrene of 12

*Present address: Institute for Nuclear Sciences, University of Ghent, Ghent, Belgium.

†Present address: Dept. of Oceanography, Florida State University, Tallahassee, Florida 32306, U.S.A. 


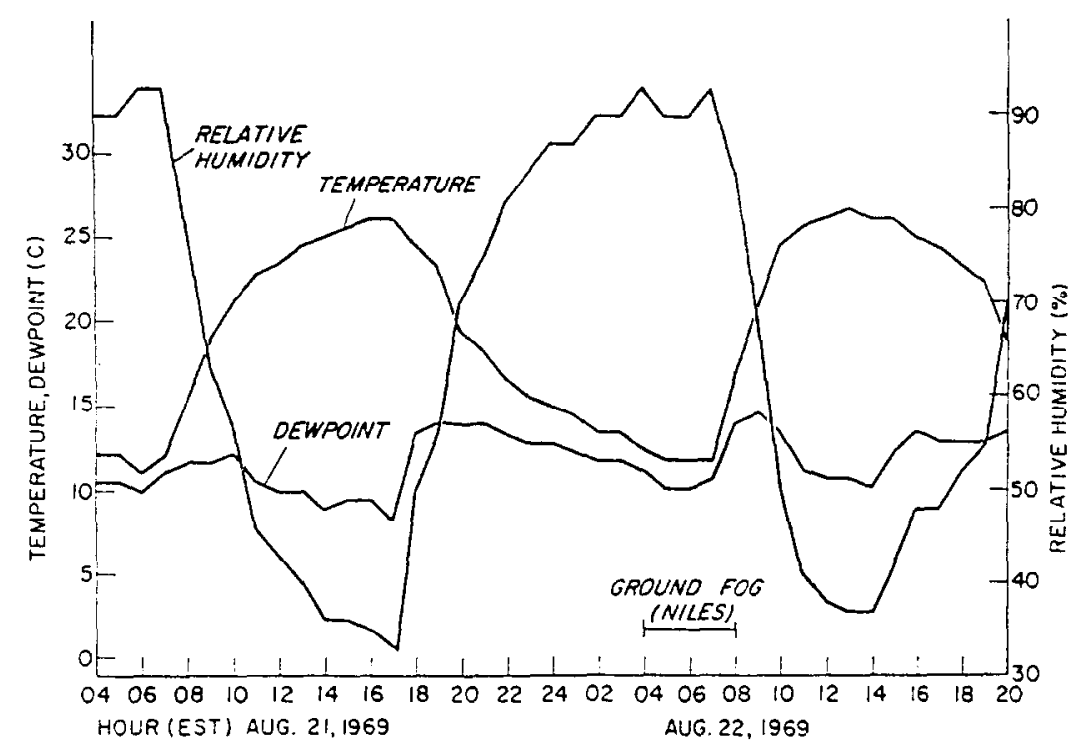

FIG. 1. Relative humidity, temperature and dewpoint during sampling.

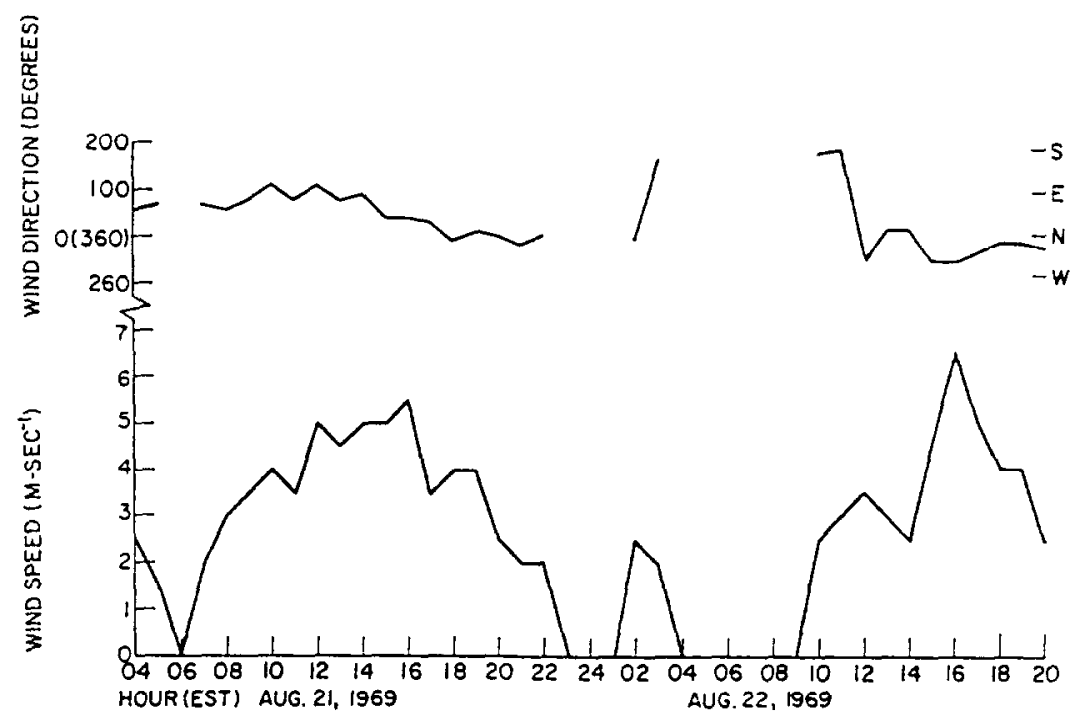

FIG. 2. Wind speed and direction during sampling.

$1-\mathrm{min}^{-1}-\mathrm{cm}^{-2}$, as opposed to the figure of $4.51-\mathrm{min}^{-1}-\mathrm{cm}^{-2}$ obtained with a high volume sampler $(20 \times 25 \mathrm{~cm}$ filter and low vacuum pump). Each sample consisted of aerosols from approximately $4 \mathrm{~m}^{3}$ of air.

Particle size distribution of the elements were determined by use of an Andersen Cascade Impactor, which separates aerosols into 7 fractions ranging from radii of roughly $8 \mu \mathrm{m}$ down to $0.1 \mu \mathrm{m}$. High purity polyethylene sheets were used as impaction surfaces and analyzed in the same manner as the filters. A backup polystyrene filter ( $25 \mathrm{~mm}$ dia.) was used to catch the smaller particles. Because of the low flow rate of 


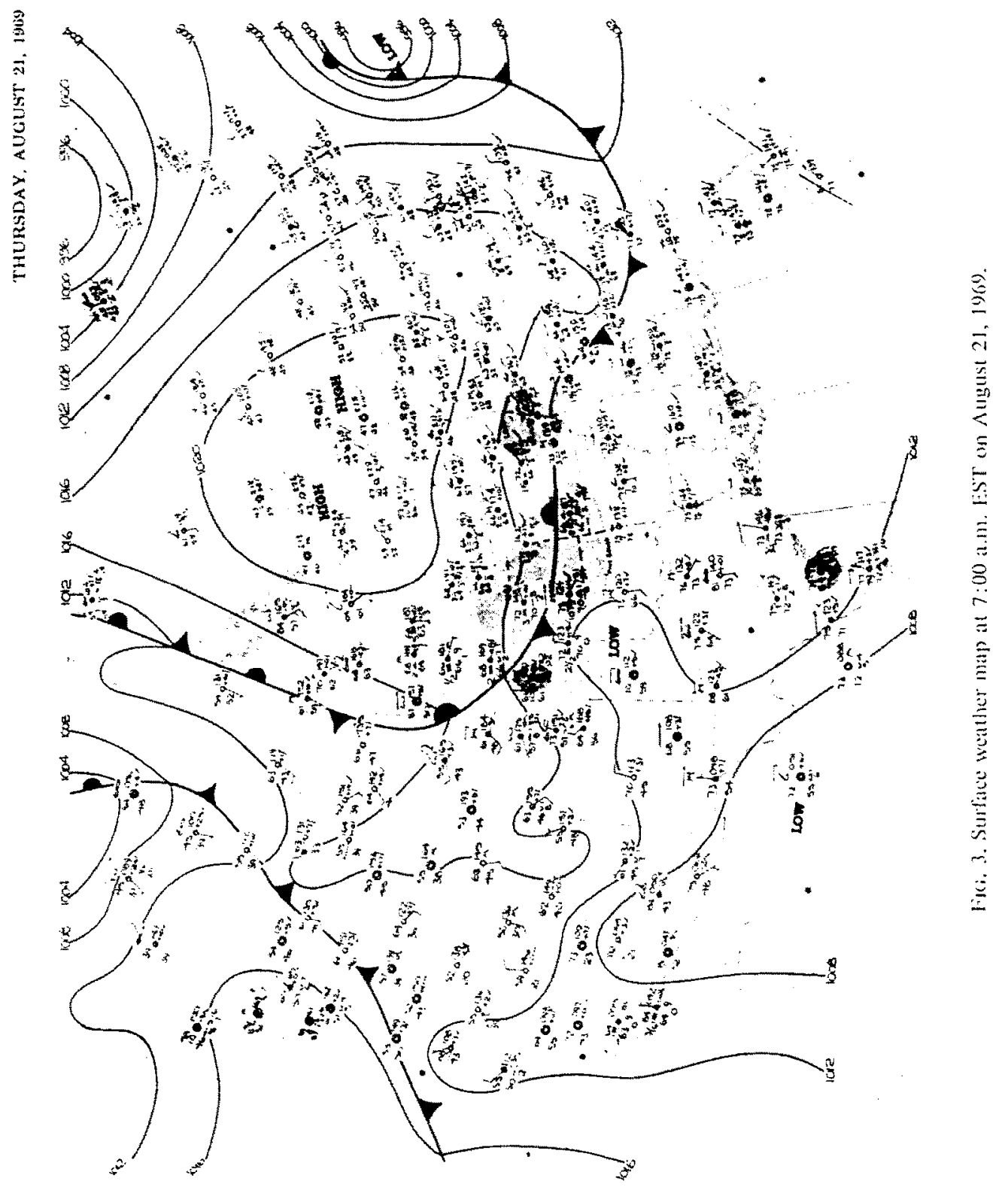




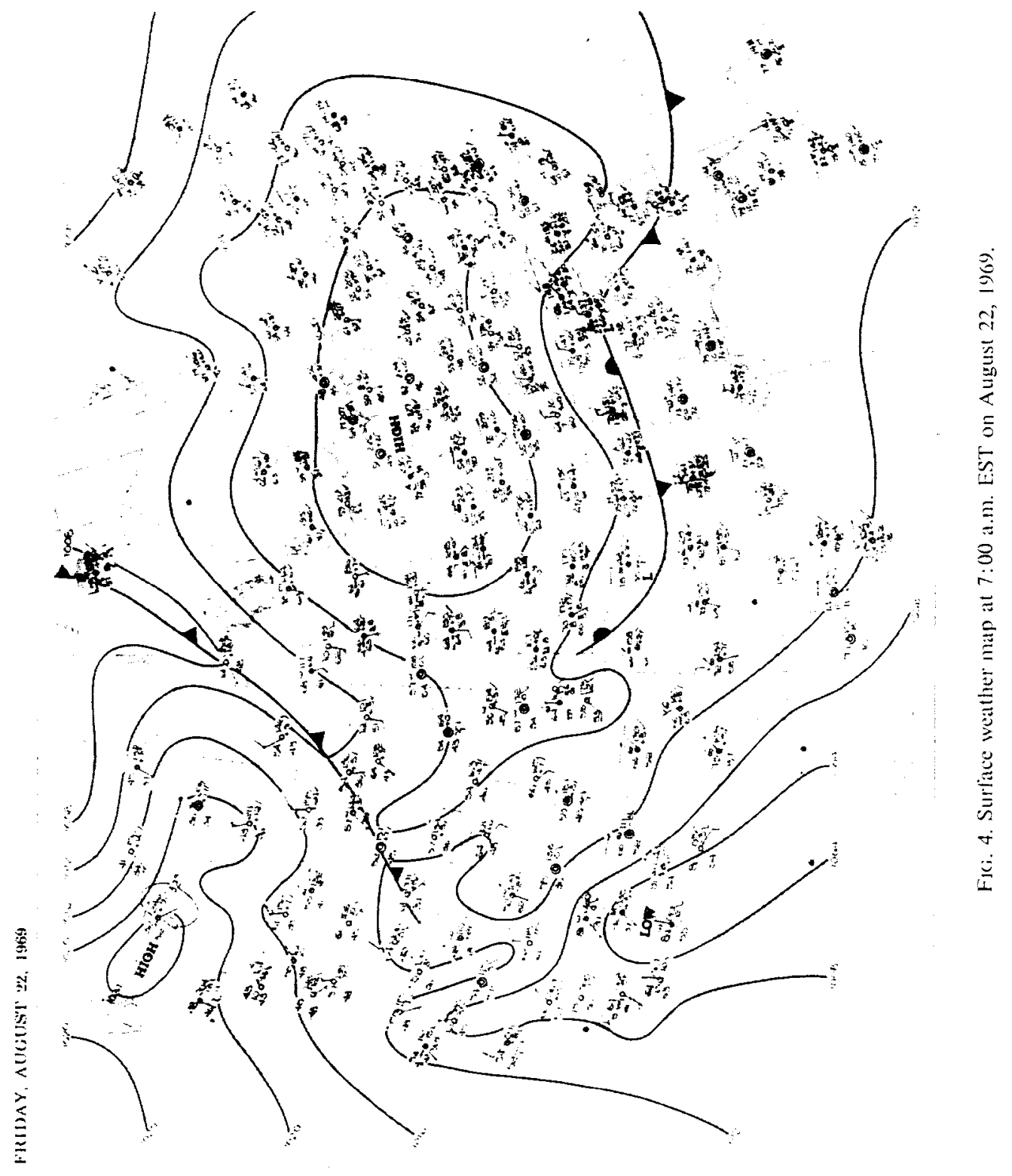


this instrument $\left(28 \mathrm{l}-\mathrm{min}^{-1}\right)$ only one size distribution sample was taken throughout the experiment. All samples were taken in a ventilated instrument shelter $1.5 \mathrm{~m}$ above ground, over short grass.

Sampling was performed in a rural area $5 \mathrm{~km}$ west of Niles, Michigan and $15 \mathrm{~km}$ north of South Bend, Indiana. It is approximately $45 \mathrm{~km}$ east of Lake Michigan and $100 \mathrm{~km}$ northeast of the heavily industrialized Northwest Indiana area. Samples were taken during $34 \mathrm{~h}$ on 21 and 22 August, 1969, when the entire north central and northeastern U.S. was under the influence of a broad Canadian high pressure area. Winds during this period varied from calm at night to $6.5 \mathrm{~m} \mathrm{~s}^{-1}$ during the afternoon, and the extreme stability of the air mass prevented any clouds from forming. Light ground fog was observed during the early morning hours of the second day. FIGURES 1 and 2 give some of the meteorological conditions recorded at ESSA WBAS South Bend, Indiana. FIGURES 3 and 4 show surface weather conditions for 7 AM EST on both sampling days.

\section{ANALYSIS}

The technique as described earlier (DAMS, 1970) was applied. The complete filter (25 mm dia.) or the complete polyethylene sheet was irradiated twice with slow neutrons in the Ford Nuclear Reactor at the University of Michigan, first for $5 \mathrm{~min}$, later for $4 \mathrm{~h}$. Each sample was counted 4 times, at 3 and 15 min after the first irradiation, and $20 \mathrm{~h}$ and 20 days after the second irradiation. Counting was performed with a $30 \mathrm{~cm}^{3} \mathrm{Ge}(\mathrm{Li})$ high resolution gamma ray detector coupled to a 4096 channel pulse height analyzer. A digital computer program was used to integrate photopeaks of the sample, compare them with standard spectra, subtract blank values, calculate concentrations of the elements in air and standard deviations on the obtained results.

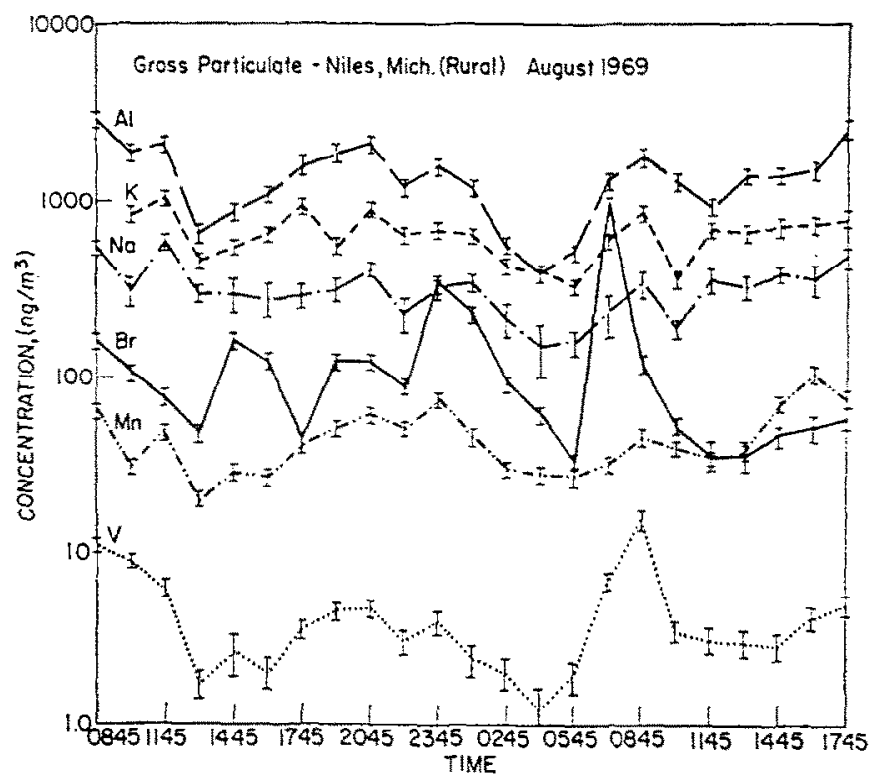

FIG. 5. Concentration variations of 6 elements during sampling. 


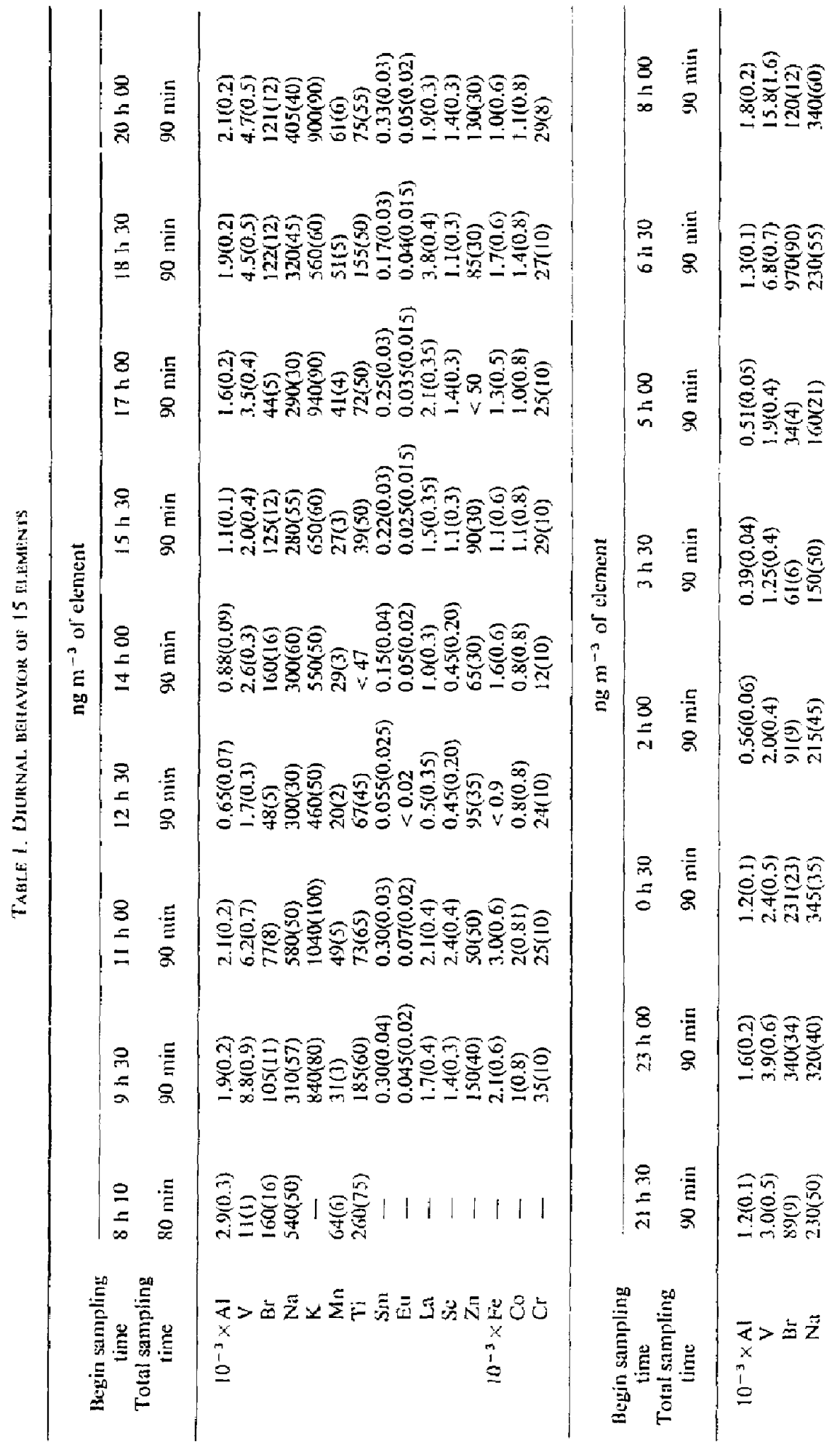




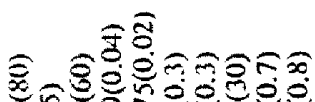

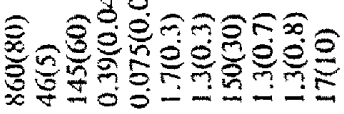

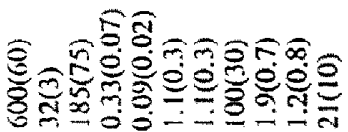

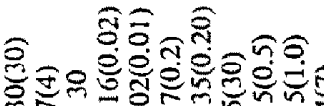

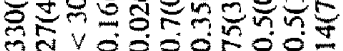

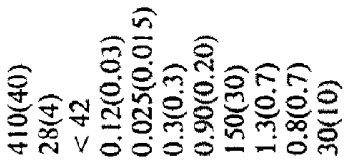

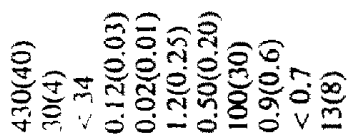

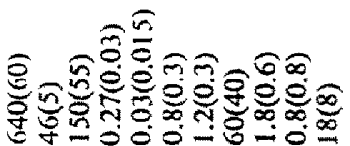

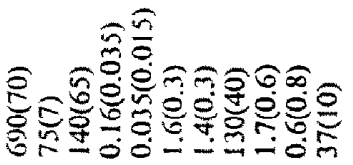

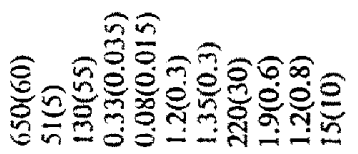

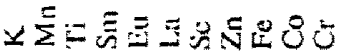
$\stackrel{m}{1}$

\begin{tabular}{|c|c|c|}
\hline$\stackrel{\varrho}{=}$ & 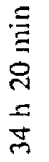 & 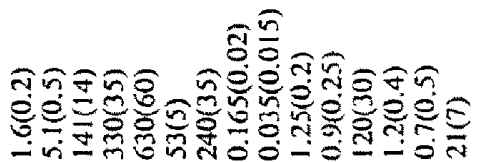 \\
\hline & $\begin{array}{l}\text { 彰 } \\
\text { 号 }\end{array}$ & 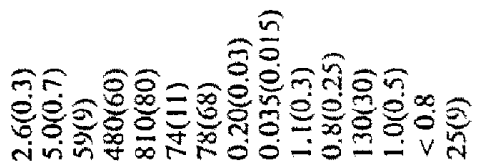 \\
\hline & 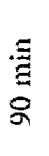 & 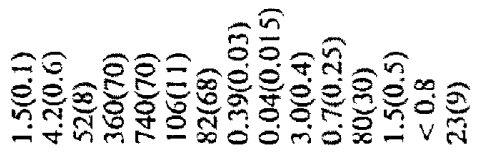 \\
\hline & 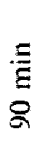 & 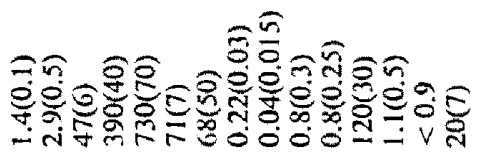 \\
\hline & 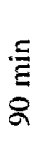 & 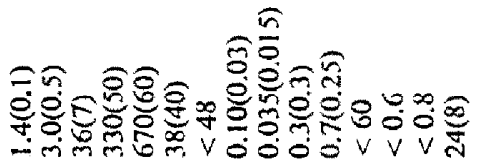 \\
\hline & $\begin{array}{l}\text { 离 } \\
\Omega\end{array}$ & 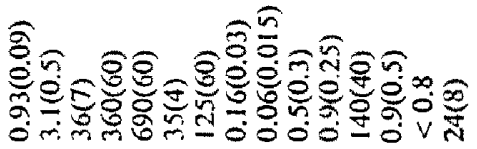 \\
\hline & 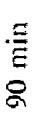 & 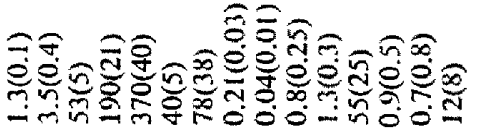 \\
\hline 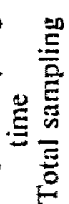 & 音 & 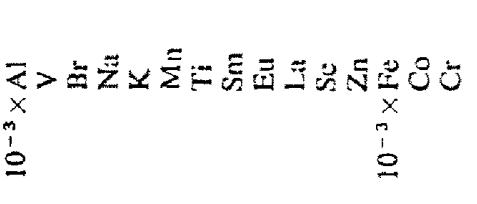 \\
\hline
\end{tabular}




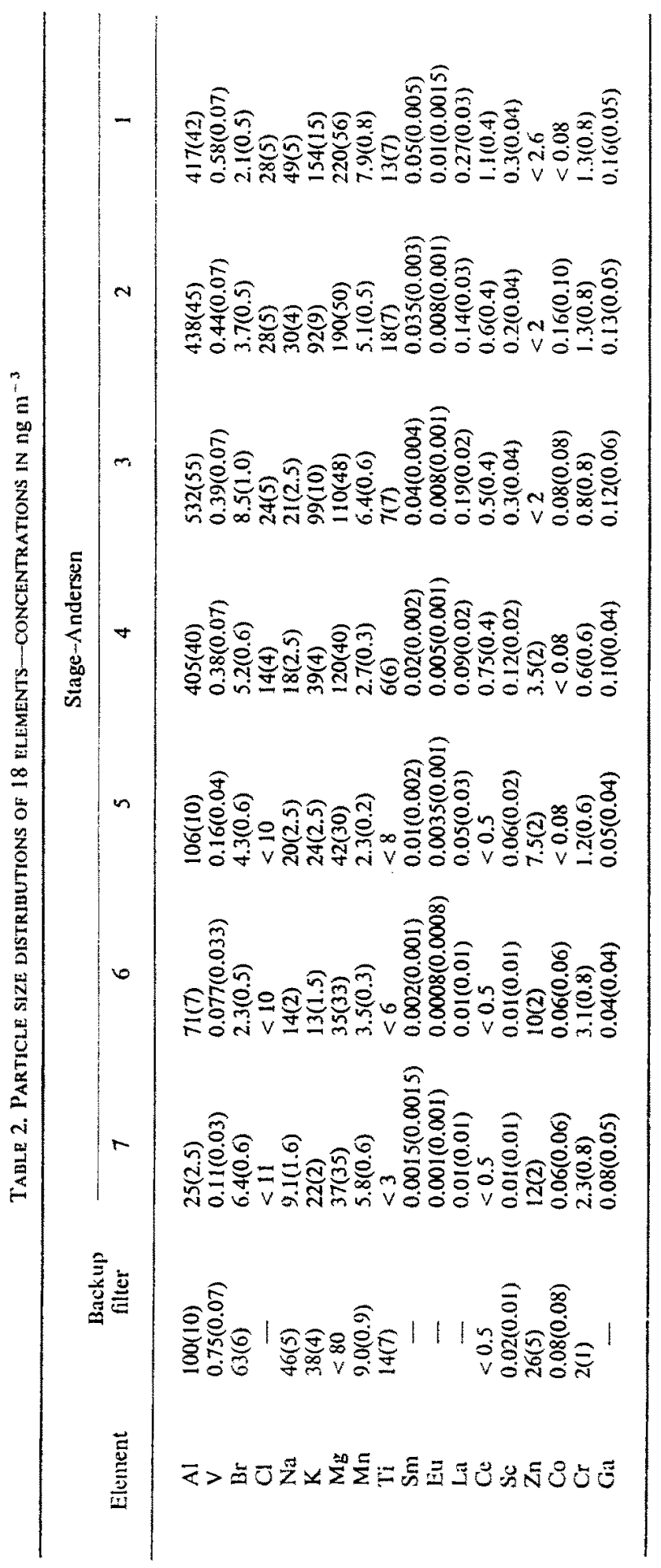




\section{RESULTS}

The results are summarized in TABLE 1 . They reveal that 15 elements could be determined in nearly all of the samples, namely $\mathrm{Al}, \mathrm{V}, \mathrm{Br}, \mathrm{Na}, \mathrm{K}, \mathrm{Mn}, \mathrm{Ti}, \mathrm{Sm}, \mathrm{Eu}$, $\mathrm{La}, \mathrm{Sc}, \mathrm{Zn}, \mathrm{Fe}, \mathrm{Co}$, and $\mathrm{Cr}$. A half dozen others ( $\mathrm{Sb}, \mathrm{As}, \mathrm{Ga}, \mathrm{Mg}, \mathrm{Cu}$, and $\mathrm{Ce}$ ) could only be determined in some samples. Due to their incompleteness the results for the latter 6 elements are not very useful and are not given in TABLE 1. The behavior of a number of representative elements is shown in FIG. 5. Particle size distributions

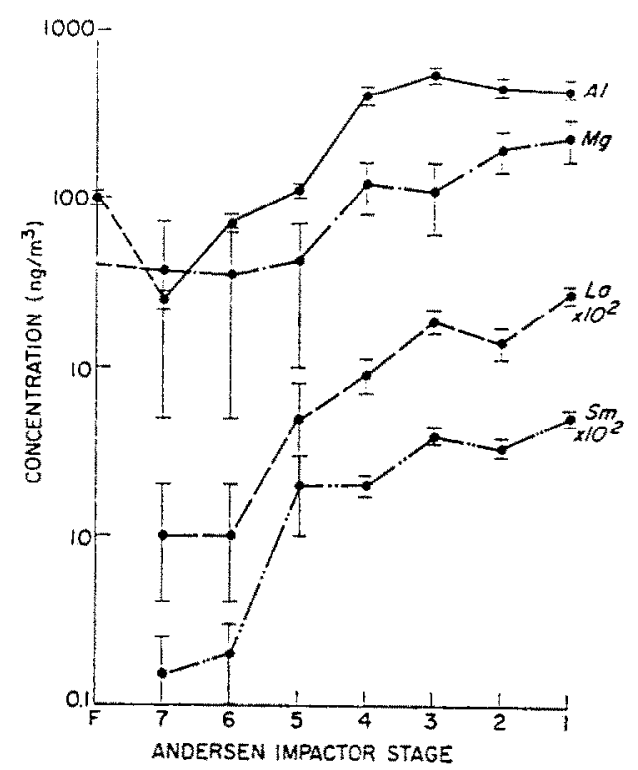

FIG. 6. Particle size distribution of 4 elements as measured with an Andersen Impactor.

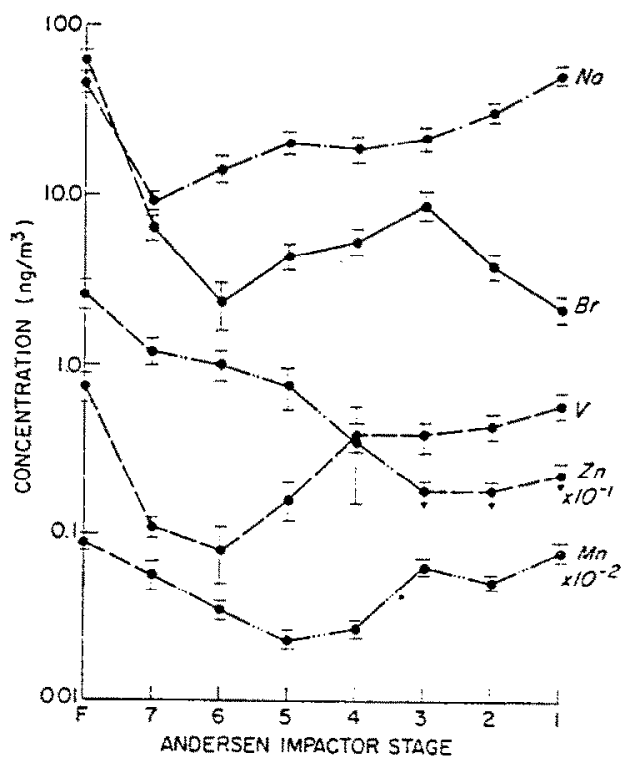

FIG. 7. Particle size distribution of 5 elements as measured with an Andersen Impactor. 
of 18 elements are summarized in TABLE 2 and 9 of these are plotted in Figs. 6 and 7 . Standard deviations are given in parentheses. If high count rates were obtained these standard deviations may be as low as 10 per cent. Because of the short sampling times the concentrations of several elements were at or near the limit of detection, and stanlard deviations of these results are much higher. On some stages of the Andersen impactor only an upper limit could be set for the concentration of several elements.

\section{DISCUSSION}

It is obvious that very large variations occur in the concentrations of several elements during a $24 \mathrm{~h}$ period. The behavior of aluminum, shown in FIG. 5 , is representative of a number of other elements such as $\mathrm{Ti}, \mathrm{Mg}, \mathrm{Sc}$ and the rare earths, Sm, Eu, and La. Concentration variations by a factor of up to 10 occur within a few hours. A number of other elements such as $\mathrm{Na}, \mathrm{K}, \mathrm{Fe}, \mathrm{Co}$, and $\mathrm{Cr}$ shows less prominent variations, on the order of 2.5 rather than 10 . The behavior of $\mathrm{Mn}$ seems to be in between these two extreme groups.

How can this consistent behavior pattern for a large number of elements be understood? Smoke, $\mathrm{SO}_{2}, \mathrm{NO}, \mathrm{NO}_{2}, \mathrm{CO}$, total oxidants, total hydrocarbons and visibility measurements have also shown consistent diurnal patterns, but with average variations of at most a factor of three (COMmins, 1967; MuNN, 1959; SUMmers, 1966; WeisMAN, 1969; U.S. Public Health Service, 1968). Being urban measurements, these variations were mostly related to variations in local source processes and city ventilation. In the present case, one deals with a rural area, and measures primarily distant sources, and diurnal meteorological variations should thus be more important. The pattern found is indeed consistent with the predicted variations of ground-level concentrations from elevated sources (U.S. Department of Health, Edtcation. AND WELFARE, 1965).

With the previous considerations in mind the following tentative explanation is offered. Particulate pollutants released at stack height during the fair weather nocturnal temperature inversion conditions tend to remain at stack height until after sunrise. Daylight hours bring ground heating and generation of turbulent motions which build rapidly upwards until the pollutant layer is reached some one to three hours after sunrise. Eddy transport of these pollutants to the surface (Hewson fumigation type I) causes the steep morning peak. Continued increase of the maximum mixing level until the midafternoon further dilutes concentrations, after which the lowering mixing level and increasing thermal stability initiates the gradual concentration increase of late afternoon and early evening.

The concentration levels of evening, being effectively cut off from elevated sources by the temperature inversion, might be expected to decrease slightly during the night. Instead, they are in most cases observed to drop rapidly during the early morning hours, often reaching the lowest levels of the sampling period. Our hypothesis is that local ground fog at the sampling site was the primary agent responsible for this decrease, due to fog droplet nucleation, probably predominantly by the giant particle component of the aerosol population, followed by enhanced sedimentation and/or impaction of the enlarged droplets. Though fog was not recorded at the more urban South Bend Airport, the temperature there decreased to within 2 degrees of the dewpoint, and the relative humidity reached a maximum of 93 per cent at the 4 a.m. and 8 a.m. observations (FIG. 1). 
Confirmation of this idea comes from the observation that in general those elements showing the largest concentration variations share two characteristics, namely relatively deep morning minima and masses concentrated on larger particles. This relation can be verified from the plots of $\mathrm{Al}$ and $\mathrm{V}$, and is also noted for $\mathrm{Ti}, \mathrm{Mg}, \mathrm{Sc}$, $\mathrm{La}, \mathrm{Eu}$, and Sm. On the other hand, elements like $\mathrm{Na}, \mathrm{K}, \mathrm{Cr}, \mathrm{Co}$, and $\mathrm{Mn}$, showing smaller diurnal variations, are more equally distributed over the $0.1-10 \mu \mathrm{m}$ size range.

We then visualize the fog formation as involving the larger and more soluble aerosols (i.e. those ordinarily collected on the first stages of the impactor), rapidly growing to a quasi-equilibrium radius of some $5-10 \mu \mathrm{m}$. Because the droplet concentration in typical fogs $\left(100-500 \mathrm{~cm}^{-3}\right.$ ) (DrNGLE, 1970) is large relative to the giant aerosol number density in continental aerosols $\left(1 \mathrm{~cm}^{-3}\right.$ ) (JUNGE, 1963) but small relative to the large particle component of the same $\left(1000 \mathrm{~cm}^{-3}\right)$, it is possible that a majority of the giant particles and a minority of the large particles served as nucleating agents. Removal of these droplets would preferentially decrease concentrations of those elements primarily in giant aerosols.

Certain of the observed elements show diurnal patterns suggestive of local sources. $\mathrm{Br}$ is the clearest example, the probable source being automotive exhaust from the road some $50 \mathrm{~m}$ distant. Distinct traffic maxima are observed about 6-7 a.m., 3-5 p.m., and 11-12 p.m., very nearly the times of $\mathrm{Br}$ maxima. Further evidence comes from the measured particle size distribution of $\mathrm{Br}$, where 65 per cent of its mass is found on the backup filter (TABLE 2). This is in agreement with the very small, condensation aerosol nature of auto exhausts, and indicates the fresh nature of most of the Br (Loucks, 1970).

The diurnal variation of $\mathrm{Zn}$ is not very consistent with the other elements, which may be partially due to the low quality of the analytical results for this element. It may however also be correlated with its predominant distribution on small particles, probably due to formation via a condensation process.

The steep morning peak makes the $\mathrm{V}$ pattern somewhat different from those of the other elements. The most important source of $\mathrm{V}$ is known to be fuel oils, but because of the August date this does not seem to provide a sufficient explanation. Heating of commercial establishments may be related to the steep morning peak, however. In addition, a considerable fraction ( 30 per cent) of this element is found on the very small particles, pointing toward a condensation formation process and recent age for its Aitken component.

\section{CONCLUSION}

The obtained results demonstrate that nondestructive neutron activation analysis can very favorably be applied to the study of diurnal variations of trace elements in the atmosphere. The 15 elements which can be measured after sampling times as short as $90 \mathrm{~min}$ in a rural area show distinct variations in diurnal behavior and should be indicators enough for the behavior of most other trace elements. It seems that the application of this technique in studies of simultaneously measured total concentration variations and particle size distribution of airborne particulates should lead to significant advances in the understanding of source processes and identification of dilution and removal mechanisms. The observed size distribution patterns remote from the source may not only reflect differing source processes but may also result in a tendency 
toward different atmospheric behavior patterns. This specific investigation was however only of an exploratory nature and further experiments under different meteorological conditions are under way in order to expand upon the tentative conclusions reported here.

\section{REFERENCES}

COMmins B. T. and WaLTER R. E. (1967) Atmospheric Environment 1, 49.

Dams R., Robbins J. A., RahN K. A. and Wnvchester J. W. (1970) Anal. Chem. 42, 861.

DAMS R., RAHN K. A. and WINCHESTER J. W. (1971) Environ. Sci. Technol. submitted.

Dingle A. N. (1970) Dept. of Met. and Ocean., Univ. of Mich., private communication.

Hewson E. W. (1960) Meteorological measuring techniques and methods in air pollution studies.

In: Industrial Hygiene and Toxicology, Vol. 3, edited by L. SnVERMAN, Interscience, New York.

JUNGE C. E. (1963) Air Chemistry and Radioactivity. Academic Press, New York.

Loucks R. H. and WINCHESTER J. W. (1970) J. geophys. Res. 75 (12), 2311.

MunN R. E. and Katz M. (1959) Int. J. Air. Pollut. 2(1), 51.

SUMmers P. W. (1966) J. Air Pollut. Control Ass. 16(4) 33.

U.S. Department of Health, Education and Welfare (1965) Meteorological Aspects of Air Pollution. Course conducted by Air Pollution Training Program, Cincinnati, Ohio.

U.S. Public HeALTh SeRvice, (1968) Air Quality Data from the National Air Sampling Networks and Contributing State and Local Networks, 1966, Durham, N.C.

Weisman B., Matheson D. M. and HIRT M. (1969) Atmospheric Environment 3, 1. 